\title{
Induction of novel mutants of Streptomyces lincolnensis with high Lincomycin production
}

\author{
Ahmed El-Sherbini', A. A. Khattab ${ }^{2}$ \\ ${ }^{1}$ Emergency Medical services Dept., Faculty of Health Sciences, Umm Al-Qura University, Al-Qunfudah, Saudi-Arabia. \\ ${ }^{2}$ Genetics and Cytology Dept., National Research Centre, Dokki, Cairo, Egypt.
}

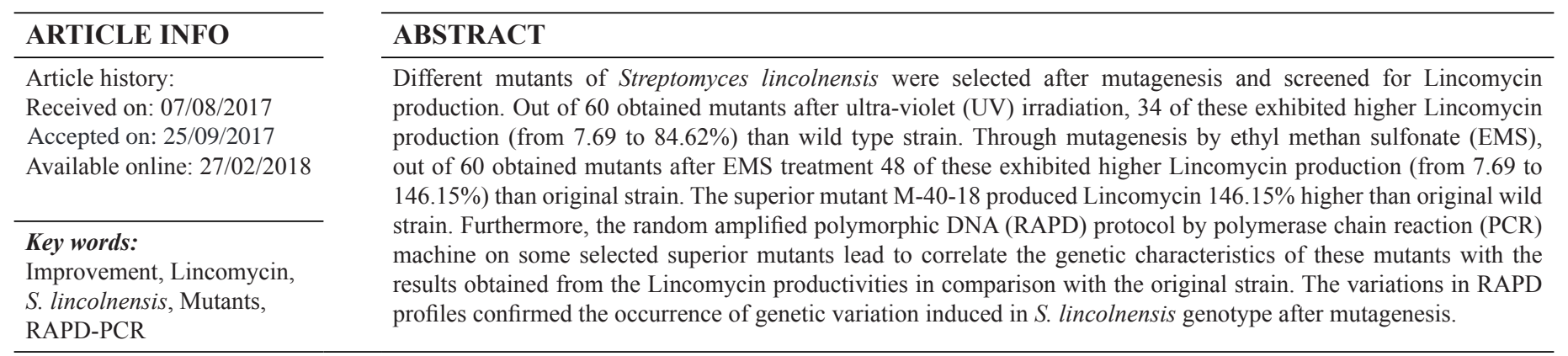

\section{INTRODUCTION}

Actinobacteria are a group of Gram-positive bacteria which produce a variety of secondary metabolites with high pharmacological and commercial interest (Anandan et al., 2016). Almost $80 \%$ of the world's antibiotics are known to be derived from Actinobacteria, mostly from the genera Streptomyces and Micromonospora (Jensen et al., 1991; Hassan, 2011). Around 7600 compounds are produced by Streptomyces species, many of which are secondary metabolites that are potent antibiotics, which has made streptomycetes the primary antibiotic-producing organisms exploited by the pharmaceutical fields (Ramesh and Mathivanan, 2009; Jensen et al., 2007). Streptomyces species have been extensively studied since they have been recognized as important sources of antibiotics. In fact, about $60 \%$ of the antibiotics used in agriculture and horticulture have been obtained from Streptomyces spp. (Hwang et al., 2001). Lincomycin was

\section{${ }^{*}$ Corresponding Author}

Ahmed El-Sherbini; Emergency Medical services Dept., Faculty of Health Sciences, Umm Al-Qura University, Al-Qunfudah, Saudi-Arabia. E-mail:elsherbini1@gmail.com isolated in 1962 from a soil actinomycete found near Lincoln, Nebraska, which gave origin to its name (Stratton, 1998). The actinomycete was identified as Streptomyces lincolnensis var. lincolnensis, a new streptomycete species. Lincomycin proved to be a member of a new class of antibiotics characterised by an alkyl 6-amino-6,8-dideoxy-1-thio-D-erythro- $\alpha$-D-galactooctopyranoside joined with a proline moiety by an amide linkage (Spizek and Rezanka, 2004a). It is applied for the treatment of diseases caused by Gram-positive bacteria (Spizek and Rezanka, 2004b). Lincomycin block the growth mainly of Gram-positive bacteria. It is used in both human and veterinary medicine. Their mechanism of action is via inhibition of protein synthesis in sensitive Gram-positive microorganisms. It is inactive against Gram-negative bacteria but it's active against anaerobic bacteria and some protozoa (Spizek et al., 2004a).

Many studies have been established to improve the fermentation performance of lincomycin by environmental conditions (Kuo et al., 1992; Spizek and Rezanka, 2004b; Semenova et al., 1994; Choi and Cho, 2004; Young et al., 1985). On the other hand, other advanced studies have been established to improve the fermentation performance of lincomycin by genetic improvement protocols (Jin et al., 
2002a, b). The screening of the fermentative performance after mutagenesis can be occurred to obtain the best strains for Lincomycin production (Xuewei et al., 2016).

The technique of RAPD has been shown to be more benefit in detection and assay of genetic variability of the different bacterial isolates. Many studies cite the RAPD as ideal protocol for assay of genomic variability. This method has been used to compare intra- and interspecific differences in bacteria (Williams et al., 1990; Ikeh 2003). Current literature did not reveal any use of mutagenesis by UV and EMS to improve Lincomycin production by Streptomyces lincolnensis NRRL 2936. Therefore, this work was established to take the benefit of mutagenesis in $S$. lincolnensis to obtain lincomycin overproducing strains. So, the goal of the present work was to choose of mutagenesis and RAPD protocols to enhancement the Lincomycin production by S. lincolnensis NRRL 2936.

\section{MATERIALS AND METHODS}

\section{Materials}

\section{Microorganisms}

The Streptomyces lincolnensis NRRL 2936 was obtained from Northern Regional Research Laboratories (NRRL), Peoria, IL, USA and used for lincomycin production. Bacillus subtilis NRRL 543 was used as the test organisms for lincomycin assay. This strain was obtained NRRL also.

\section{Culture media}

The culture of $S$. lincolnensis was maintained on spore medium slants (Zhe and Ruishen, 1998) at $28^{\circ} \mathrm{C}$ and was subcultured at monthly intervals.

\section{Methods}

\section{Culture conditions and inoculum preparation}

The production of Lincomycin were studied in the basal medium (Young and Kempe, 1985) consisting of: glucose $30 \mathrm{~g} / \mathrm{L}, \mathrm{Na}_{2}$-Citrate. $2 \mathrm{H}_{2} 03.4 \mathrm{~g} / \mathrm{L}, \mathrm{NH}_{4} \mathrm{NO}_{3}, 2.5 \mathrm{~g} / \mathrm{L}, \mathrm{K}_{2} \mathrm{HPO}_{4}$, $5.0 \mathrm{~g} / \mathrm{L}, \mathrm{MgSO}_{4} \cdot 7 \mathrm{H}_{2} 01 \mathrm{~g} / \mathrm{L}, \mathrm{ZnSO}_{4} .7 \mathrm{H}_{2} \mathrm{O} 1 \mathrm{mg} / \mathrm{L}, \mathrm{Fe}_{2} \mathrm{SO}_{4}$. $7 \mathrm{H}_{2} 01 \mathrm{mg} / \mathrm{L}$, and $\mathrm{NaCl} 0.5 \mathrm{~g} / \mathrm{L}$ and the medium was adjusted to $\mathrm{pH} 7.2$ and sterilized. For the development of inoculum, $20 \mathrm{ml}$ of Seed medium (Zhe and Ruishen, 1998) broth was placed in a $50-\mathrm{ml}$ Erlenmeyer flask, the $\mathrm{pH}$ was adjusted to 7.0 , and the medium was sterilized. It was inoculated with a well-sporulated slant culture of $S$. lincolnensis ( 8 days old) and kept at $180 \mathrm{rpm}$ on a rotary shaker for $60 \mathrm{~h}$ at $28^{\circ} \mathrm{C}$. A $0.5-\mathrm{ml}$ portion of this broth was used to inoculate $50 \mathrm{ml}$ of the production medium contained in a 250-ml Erlenmeyer flask. The flasks were kept on $250 \mathrm{rpm}$ a rotary shaker. Incubation temperature was $28^{\circ} \mathrm{C}$.

\section{UV-mutagenesis}

The spores of Streptomyces lincolnensis from old slants (8 days) were suspended in sterile distilled water and exposed to UV-light for $0,6,12$ and 15 minutes at a distance of $20 \mathrm{~cm}$. After irradiation, the treated spore suspensions were protected from light for two hours. Appropriate dilutions were spread on spore medium and incubated at $28{ }^{\circ} \mathrm{C}$ for three days. The growing colonies were transplanted on spore medium slants for the forward assay of lincomycin productivities.

\section{EMS-mutagenesis}

The spores of Streptomyces lincolnensis from old slants ( 8 days) were suspended in sodium phosphate buffer (0.1M, pH 7.0) and treated with $200 \mathrm{mM}$ of EMS for 20, 40 and 60 minutes. Appropriate dilutions were spread on spore medium and incubated at $28{ }^{\circ} \mathrm{C}$ for three days. The growing colonies were transplanted on spore medium slants for the forward assay of lincomycin productivities.

\section{Assay of antibiotic production}

The production of lincomyces of each colony was tested by using B. subtilis as the test organisms on Nutrient agar (NA). The antibiotic productivity was examined for the individual colony by inoculation in the broth of production medium. The incubated production medium flasks were examined for the contents of antibiotics by a paper disk diffusion assay. Standard curves were prepared with authentic Lincomycin (Table 1).

Table 1: The inhibition zone diameters using different concentrations of lincomycin.

\begin{tabular}{lc}
\hline Lincomycin concentration $(\boldsymbol{\mu g} / \mathbf{m l})$ & $\begin{array}{c}\text { Inhibition zone with } \\
\text { B. subtilis }(\mathbf{m m})\end{array}$ \\
\hline 120 & 9 \\
240 & 11 \\
410 & 13 \\
530 & 15 \\
650 & 18 \\
850 & 21 \\
\hline
\end{tabular}

Total DNA isolation from mutant strains

Total DNA from superior mutants was extracted according to i-genomic BYF DNA extraction Mini Kit, iNtRON Biotechnology Inc., South Korea. The concentration and purity of the isolated DNA were assayed according to the UV-absorbance at 260 and $280 \mathrm{~nm}$ using spectrophotometer according to Sambrook et al., (1989).

\section{Molecular analysis of novel mutants}

Ready-To-Go PCR Beads (GE Healthcare, Lifescience, Illustra, HP7 9NA UK, Product Booklet Code: 27-9559-01) were applied for PCR protocols. Each bead contains all of the important reagents, except primer and DNA template, to run the amplification of $25 \mu \mathrm{l}$ PCR reactions. Three different primers were used in the present study. The first primer (P1) sequence was 5'-CAT ACC CCC GCC GTT-3'. The second primer (P2) sequence was 5'-GTG TTG TGG TCC ACT-3'. The third primer (P3) sequence was 5'-TGA GTG GTC TAC GTG-3'. All primers were supplied by Operon Technologies Company, Netherlands. To each PCR bead, $12 \mathrm{ng}$ of the used random primer and $40 \mathrm{ng}$ of the 
purified DNA sample were added. The total volume of the amplification reaction was completed to $25 \mu \mathrm{l}$ using sterile distilled water. The amplification protocol was carried out as follows: Denaturation at $95^{\circ} \mathrm{C}$ for five min. Thirty-five cycles each consists of the following segments: Denaturation at $95^{\circ} \mathrm{C}$ for one min; primer annealing for two min. according to $\mathrm{GC}$ ratio of each primer and incubation at $72^{\circ} \mathrm{C}$ for two min. for DNA polymerization. At the end, hold the PCR at $4^{\circ} \mathrm{C}$ till analysis. The amplified DNA products from RAPD analysis were electrophorated on $1.0 \%$ agarose gel and $1 \mathrm{X}$ TBE buffer at consistent 100 volt for about $2 \mathrm{hrs}$. The different band sizes were determined against 100 bp ladder (Vivantis \# NL 1407-Malaysia) and the obtained banding profiles were stained with $0.5 \mu \mathrm{g} / \mathrm{ml}$ ethidium bromide and photographed using Gel Documentation System with UV Transeliminator.

\section{RESULTS AND DISCUSSION}

\section{Mutation induction response of $S$. lincolnensis}

The microorganism $S$. lincolnensis was exposed to UV light and EMS mutagen. When the Spores suspension was irritated to UV-light as mentioned previously in the adopted materials and methods. Data in Table (2) showed that the survival percentages sharply decreased gradually by increasing treatment time. Moreover, data in Table (3) showed the same trend for survival percentages after EMS mutagenesis, since the highest survival percentage was recorded following the exposure time $(20 \mathrm{~min})$, followed by those obtained from the spores suspensions exposed to 40 and $60 \mathrm{~min}$.

Table 2: Effect of UV on viability of S. lincolnensis NRRL 2936.

\begin{tabular}{lcc}
\hline \multirow{2}{*}{ Exposure time (min) } & \multicolumn{2}{c}{ Survival } \\
\cline { 2 - 3 } & No. & \% \\
\hline 0 & 1137 & 100.00 \\
6 & 584 & 51.36 \\
12 & 205 & 18.03 \\
15 & 62 & 5.45 \\
\hline
\end{tabular}

Table 3: Effect of EMS on viability of S. lincolnensis NRRL 2936.

\begin{tabular}{lcc}
\hline \multirow{2}{*}{$\begin{array}{l}\text { Exposure time } \\
(\mathbf{m i n})\end{array}$} & \multicolumn{2}{c}{ Survival } \\
\cline { 2 - 3 } & No. & $\%$ \\
\hline 0 & 816 & 100.00 \\
20 & 155 & 19.00 \\
40 & 39 & 4.78 \\
60 & 28 & 3.43 \\
\hline
\end{tabular}

\section{Mutation induction and lincomycin productivity}

The change in DNA nucleotide sequence is basically produced by mutation. Generally, the induction of mutations are done by the use of mutagenic agents that interact with DNA. Since, the natural mutations are rare in comparison of the induced mutations, many type of change in DNA sequence (base pair substitution, insertion, deletion) are induced randomly in a microbial DNA by the application of chemical and physical mutagenic agents. The popular mutagens used for bacterial strain improvement are UV and EMS which typically produce different of point mutations in the bacterial DNA. Mutagenesis of industrial microbial strains is widely used for the enhancement of the antibiotic production by Streptomyces (Thoma, 1971; El-Bondkly and Khattab, 2004; Zhihua et al., 2006; Xiang-Jing et al., 2009; Khattab and El-Bondkly, 2006; Khattab, 2011).

Table (4) presents the licomycin production of 20 randomly selected mutants out of the survived isolates following the exposure of $S$. lincolnensis to UV-light for 6 min compared to the untreated wild strain. These results indicated that the majority of the tested mutants produced lincomycin higher than their wild parental strain. Meanwhile, four mutants, i.e., UV-6-5, UV-6-9, UV-6-15 and UV-6-18 proved to have the same efficiency lincomycin productivity of the wild strain. On the other hand, seven mutants produced lincomycin lower than their wild parental strain. The highest lincomycin producer mutant was UV-6-13 since it showed 61.54 percent production higher than the wild strain.

Results presented in Table (5) clearly showed that, out of selected 20 mutants which was exposed to UV-light for $12 \mathrm{~min}$. The results indicated that 13 out of 20 mutants produced lincomycin more than the original strain. The mutants exceeded the wild type strain with variable percentages ranged from $7.69 \%$ (UV-12-4) and up to $84.62 \%$ (UV-12-8). Moreover, other 7 mutants produced lincomycin lowers than their original parental strain.

Data in Table (6) also indicated that, in spite of no one of the tested mutants lost completely its lincomycin productivity, however, five mutants produced the lower amount of lincomycin of the wild type strain. Meanwhile, three mutants, i.e., UV-15-14, UV-15-15 and UV-15-17 proved to have the same efficiency lincomycin productivity of the wild strain. The highest lincomycin producer mutant was UV-15-6 since it showed 84.62 percent production higher than the wild strain.

Similarly, other authors have been used UV light successfully to induce mutants with improved productivity of antibiotic from Streptomyces (El-Bondkly and Khattab, 2004; Zhihua et al., 2006; Xiang-Jing et al., 2009; Khattab and El-Bondkly, 2006; Khattab, 2011). For many reasons, it appeared that UV-induced mutants were more stable through long term of generation and sub-culturing (Thoma, 1971). Also, the obtained results were in agreement with those obtained by Khattab (2011). He improved kanamycin production by Streptomyces kanamyceticus using UV-light mutagenesis and the results indicated that, the majority of the resistant mutants to $250 \mu \mathrm{g} / \mathrm{ml}$ of Kanamycin obtained after different UV-doses were produced kanamycin higher than their original parental strain. The highest Kanamycin producer mutant was K12/4 since it showed 66.67 percent production higher than the original strain. 
Table 4: Lincomycin productivity of different mutants obtained following exposure of S. lincolnensis to UV-light for $6 \mathrm{~min}$.

\begin{tabular}{lcc}
\hline Mutant No. & $\begin{array}{c}\text { Inhibition zone with } \\
\text { B. subtilis }(\mathbf{m m})\end{array}$ & \% from W.T \\
\hline W.T & 13 & 100.00 \\
UV-6-1 & 12 & 92.31 \\
UV-6-2 & 14 & 107.69 \\
UV-6-3 & 9 & 69.23 \\
UV-6-4 & 15 & 115.38 \\
UV-6-5 & 13 & 100.00 \\
UV-6-6 & 16 & 123.08 \\
UV-6-7 & 9 & 69.23 \\
UV-6-8 & 11 & 84.62 \\
UV-6-9 & 13 & 100.00 \\
UV-6-10 & 18 & 138.46 \\
UV-6-11 & 8 & 61.54 \\
UV-6-12 & 15 & 115.38 \\
UV-6-13 & 21 & 161.54 \\
UV-6-14 & 14 & 107.69 \\
UV-6-15 & 13 & 100.00 \\
UV-6-16 & 15 & 115.38 \\
UV-6-17 & 9 & 69.23 \\
UV-6-18 & 13 & 100.00 \\
UV-6-19 & 16 & 123.08 \\
UV-6-20 & 8 & 61.54 \\
\hline
\end{tabular}

Table 5: Lincomycin productivity of different mutants obtained following exposure of S. lincolnensis to UV-light for $12 \mathrm{~min}$.

\begin{tabular}{lcc}
\hline Mutant No. & $\begin{array}{c}\text { Inhibition zone with } \\
\text { B. subtilis }(\mathbf{m m})\end{array}$ & \% from W.T \\
\hline W.T & 13 & 100.00 \\
UV-12-1 & 15 & 115.38 \\
UV-12--2 & 18 & 138.46 \\
UV-12-3 & 9 & 69.23 \\
UV-12-4 & 14 & 107.69 \\
UV-12-5 & 21 & 161.54 \\
UV-12-6 & 15 & 115.38 \\
UV-12-7 & 11 & 84.62 \\
UV-12-8 & 24 & 184.62 \\
UV-12-9 & 9 & 69.23 \\
UV-12-10 & 20 & 153.85 \\
UV-12-11 & 18 & 138.46 \\
UV-12-12 & 16 & 123.08 \\
UV-12-13 & 14 & 107.69 \\
UV-12-14 & 11 & 84.62 \\
UV-12-15 & 8 & 61.54 \\
UV-12-16 & 18 & 138.46 \\
UV-12-17 & 9 & 69.23 \\
UV-12-18 & 22 & 169.23 \\
UV-12-19 & 12 & 92.31 \\
UV-12-20 & 18 & 138.46 \\
\hline
\end{tabular}

Table 6: Lincomycin productivity of different mutants obtained following exposure of S. lincolnensis to UV-light for $15 \mathrm{~min}$.

\begin{tabular}{lcc}
\hline Mutant No. & $\begin{array}{c}\text { Inhibition zone with } \\
\text { B. subtilis }(\mathbf{m m})\end{array}$ & \% from W.T \\
\hline W.T & 13 & 100.00 \\
UV-15-1 & 18 & 138.46 \\
UV-15-2 & 14 & 107.69 \\
UV-15-3 & 16 & 123.08 \\
UV-15-4 & 8 & 61.54 \\
UV-15-5 & 16 & 123.08 \\
UV-15-6 & 24 & 184.62 \\
UV-15-7 & 9 & 69.23 \\
UV-15-8 & 12 & 92.31 \\
UV-15-9 & 11 & 84.62 \\
UV-15-10 & 18 & 138.46 \\
UV-15-11 & 14 & 107.69 \\
UV-15-12 & 15 & 115.38 \\
UV-15-13 & 16 & 123.08 \\
UV-15-14 & 13 & 100.00 \\
UV-15-15 & 13 & 100.00 \\
UV-15-16 & 13 & 161.54 \\
UV-15-17 & 13 & 100.00 \\
UV-15-18 & 21 & 123.08 \\
UV-15-19 & 169.23 \\
UV-15-20 & 13.62 \\
\hline & 13 & \\
\hline & 13 & \\
\hline
\end{tabular}

The original strain $S$. lincolnensis was treated with $200 \mathrm{mM}$ of EMS for different periods as mentioned at Materials and Methods. Table (7) presents lincomycin productivity of randomly selected 20 mutants following EMS treatment for $20 \mathrm{~min}$. The results presented in Table (7) showed that this treatment enhanced the lincomycin productivity up to 107.69 percent from the mutant E-20-19 over the original strain \{as shown in Figure 1\}. The next highest producer mutant was E-20-15 which exceeded their original strain with 92.31 percent. Moreover, extra 10 mutants exhibited higher productivity than the parental strain with percentages ranged from 7.69 (E-20-7) to 84.62 (E-20-12).

Results presented in Table (8) clearly showed that, out of selected 20 mutants which was treated with EMS for 40 min. The obtained results showed an opposite trend since the majority of the tested mutants (17 mutants) out of 20 mutants produced lincomycin more than the original strain. The mutants exceeded the wild type strain with variable percentages ranged from $7.69 \%$ (M-40-4) and up to $146.15 \%$ (M-40-18) \{as shown in Figure 1\}. Moreover, other 3 mutants produced lincomycin lower than their original parental strain. The results presented in Table (9) showed that the highest lincomycin productivity (130.77\%) was obtained from the isolate S-60-8 (Figure 1). Meanwhile, 17 isolates produced lincomycin higher than the original strain but lower than the superior mutant S-60-8. On the other hand, one mutant $(\mathrm{S}-60-12)$ of the tested 20 ones 
lost some of their productivity in comparison to their parental strain. Another one mutant (S-60-15) proved to have the same efficiency lincomycin productivity of the wild strain. The obtained results were in agreement with those obtained by Khattab, (2011). He improved kanamycin production by Streptomyces kanamyceticus using UV-light mutagenesis and the results indicated that, the majority of the resistant mutants to $250 \mu \mathrm{g} / \mathrm{ml}$ of Kanamycin obtained after different UV-doses were produced kanamycin higher than their original parental strain. The highest Kanamycin producer mutant was K12/4 since it showed 66.67 percent production higher than the original strain.

In general, it could be concluded that the mutagenic treatments with proved to EMS be effective over UV-light for the enhancement of the lincomycin production. Moreover, it is worthy to postulate that using EMS for $40 \mathrm{~min}$. was the highest effective dose since the highest producer mutant (M-40-18) exhibited higher lincomycin productivity than their untreated wild type strain which used commercially at International level for lincomycin production, were also.

Table 7: Lincomycin productivity of different mutants obtained following treatment of S. lincolnensis with EMSs for $20 \mathrm{~min}$.

\begin{tabular}{|c|c|c|}
\hline Mutant No. & $\begin{array}{l}\text { Inhibition zone with } \\
\text { B. subtilis }(\mathrm{mm})\end{array}$ & $\%$ from W.T \\
\hline W.T & 13 & 100.00 \\
\hline E-20-1 & 18 & 138.46 \\
\hline E-20-2 & 11 & 84.62 \\
\hline E-20-3 & 13 & 100.00 \\
\hline E-20-4 & 11 & 84.62 \\
\hline E-20-5 & 8 & 61.54 \\
\hline E-20-6 & 13 & 100.00 \\
\hline E-20-7 & 14 & 107.69 \\
\hline E-20-8 & 20 & 153.85 \\
\hline E-20-9 & 16 & 123.08 \\
\hline E-20-10 & 16 & 123.08 \\
\hline E-20-11 & 18 & 138.46 \\
\hline E-20-12 & 24 & 184.62 \\
\hline E-20-13 & 21 & 161.54 \\
\hline E-20-14 & 13 & 100.00 \\
\hline E-20-15 & 25 & 192.31 \\
\hline E-20-16 & 11 & 84.62 \\
\hline E-20-17 & 21 & 161.54 \\
\hline E-20-18 & 16 & 123.08 \\
\hline E-20-19 & 27 & 207.69 \\
\hline E-20-20 & 18 & 138.46 \\
\hline
\end{tabular}

Table 8: Lincomycin productivity of different mutants obtained following treatment of S. lincolnensis with EMS for $40 \mathrm{~min}$.

\begin{tabular}{lcc}
\hline Mutant No. & $\begin{array}{c}\text { Inhibition zone with } \\
\text { B. subtilis }(\mathbf{m m})\end{array}$ & \% from W.T \\
\hline W.T & 13 & 100.00 \\
M-40-1 & 23 & 176.92 \\
M-40-2 & 25 & 192.31 \\
M-40-3 & 22 & 169.23 \\
M-40-4 & 14 & 107.69 \\
M-40-5 & 18 & 138.46 \\
M-40-6 & 18 & 138.46 \\
M-40-7 & 16 & 123.08 \\
M-40-8 & 15 & 115.38 \\
M-40-9 & 18 & 138.46 \\
M-40-10 & 9 & 69.23 \\
M-40-11 & 27 & 207.69 \\
M-40-12 & 28 & 215.38 \\
M-40-13 & 11 & 84.62 \\
M-40-14 & 11 & 84.62 \\
M-40-15 & 30 & 230.77 \\
M-40-16 & 18 & 138.46 \\
M-40-17 & 16 & 123.08 \\
M-40-18 & 32 & 246.15 \\
M-40-19 & 15 & 115.38 \\
M-40-20 & 26 & 200.00 \\
\hline
\end{tabular}

Table 9: Lincomycin productivity of different mutants obtained following treatment of S. lincolnensis with EMS for $60 \mathrm{~min}$.

\begin{tabular}{lcc}
\hline Mutant No. & $\begin{array}{c}\text { Inhibition zone with } \\
\text { B. subtilis }(\mathbf{m m})\end{array}$ & \% from W.T \\
\hline W.T & 13 & 100.00 \\
S-60-1 & 25 & 192.31 \\
S-60-2 & 16 & 123.08 \\
S-60-3 & 14 & 107.69 \\
S-60-4 & 21 & 161.54 \\
S-60-5 & 22 & 169.23 \\
S-60-6 & 18 & 138.46 \\
S-60-7 & 27 & 207.69 \\
S-60-8 & 30 & 230.77 \\
S-60-9 & 28 & 215.38 \\
S-60-10 & 24 & 184.62 \\
S-60-11 & 16 & 123.08 \\
S-60-12 & 11 & 84.62 \\
S-60-13 & 16 & 123.08 \\
S-60-14 & 15 & 115.38 \\
S-60-15 & 13 & 100.00 \\
S-60-16 & 14 & 107.69 \\
S-60-17 & 18 & 161.54 \\
S-60-18 & 24 & 192.31 \\
S-60-19 & 25 & 138.46 \\
S-60-20 & 184.62 \\
\hline & &
\end{tabular}




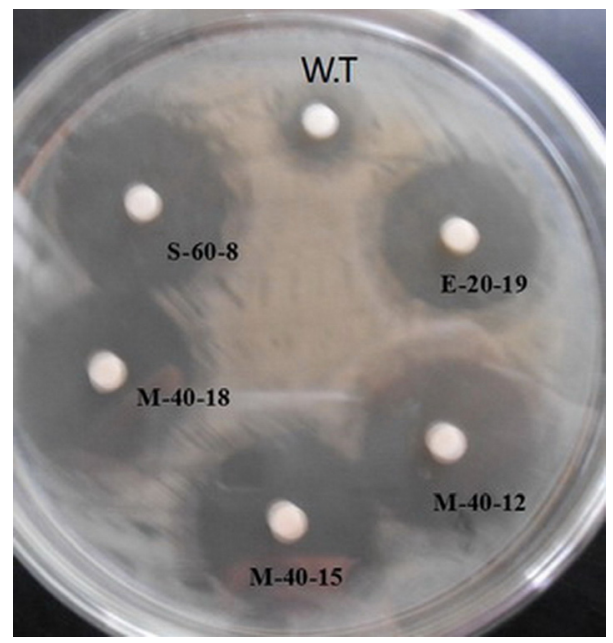

Fig. 1: Lincomycin production of S. lincolnensis NRRL 2936 (W.T) against superior mutant strains of E-20-19, M-40-12, M-40-15, M-40-18 and S-60-8.

Finally, we demonstrated improvement of the Lincomycin productivity (approximately over $1100 \mu \mathrm{g} \mathrm{ml}^{-1}$ ) of the industrial strain by 3.0 -fold by introducing a Lincomycin resistant mutation after EMS mutagenesis. The previous study by Krzek et al., (2000) demonstrated that, the Lincomycin production of wild natural producers $\left(10-100 \mu \mathrm{g} \mathrm{ml}^{-1}\right)$ and overproducing industrial strains $\left(100-1000 \mu \mathrm{g} \mathrm{ml}^{-1}\right)$ can be detected by thinlayer chromatography. Also, the obtained superior mutants were higher than the Streptomyces lincolnensis ATCC 25466 (the wild type industrial strain) which produced $50 \mu \mathrm{g} \mathrm{ml}^{-1}$ of Lincomycin (Koberska et al., 2008). Lee et al., (2014) found that the Lincomycin Production by $S$. lincolnensis increased by $2 \sim 3$ fold by optimization of cultivation medium. In addition they further increased the productivity by optimizing the culture condition (agitation speed, impeller type, $\mathrm{pH}$, etc.). The highest level of lincomycin produced was $350 \mathrm{mg} / \mathrm{L}$ at $240 \mathrm{~h}$ under the best operating conditions. Majerčíková et al., (2015) also studied the glucose effect on lincomycin production by $S$. lincolnensis. The results showed that the preculture medium application and glucose addition had positive effect, resulting in a remarkable increase in the lincomycin production.

\section{Molecular analysis of superior mutants}

An attempt was conducted to assay the genetic effects of mutagenic treatments on the DNA nucleotide sequence of the selected mutants compared to the original strain was also considered. Three 15-mer primers were applied using randomly amplified polymorphic DNA (RAPD) technique to detect the molecular variations between five Superior mutants and S. lincolnensis W.T. The results presented in Figure (2) presented the random amplified banding patterns of the tested mutants when primer (P1) was used. One bands with sizes of $\sim 990 \mathrm{bp}$ was detected for all tested mutants and the wild strain. Moreover, four additional bands with size of $\sim 250,450,550$ and $650 \mathrm{bp}$ were occurred (Lane 1) for the wild strain. Three mutants (lanes, 2, 3 and 4) exhibited the same banding pattern of the wild strain. On the other hand, the mutants (lanes 5 and 6) exhibited two additional bands with size of $\sim 300$, and $700 \mathrm{bp}$ and lost the band with size of $\sim 250 \mathrm{bp}$.
Using primer (P2) against the tested mutants and the wild strain (Figure 3 ) exhibited one bands with sizes of $\sim 775 \mathrm{bp}$ was detected for all tested mutants and the wild strain. One very faint band with sizes of $500 \mathrm{bp}$ was detected for the wild strain (Lanes 1). Two very faint bands with sizes of $\sim 300$ and 550 bp were detected when the DNA of mutants (Lanes 3 and 4) were used as a templates. On the other hand, the mutants (Lanes 5 and 6) exhibited two very faint amplified bands with sizes of $\sim 400$ and $800 \mathrm{bp}$.

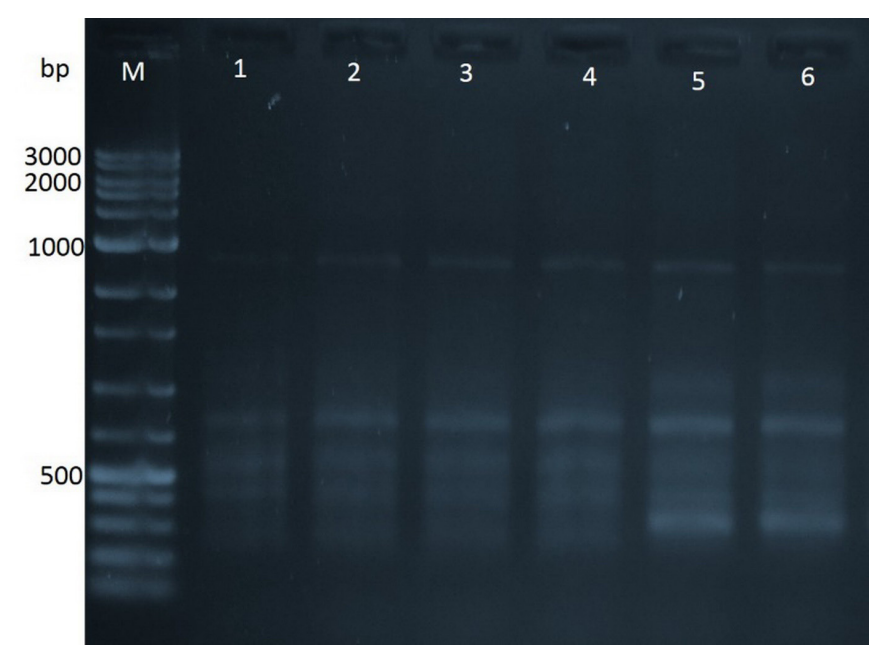

Fig. 2: DNA Photograph amplified profiles by RAPD for five best mutants (Lanes 2 to 6) and S. lincolnensis W.T (lane 1) using primer (P1) against VC100 bp plus DNA ladder Vivantis \# NL 1407-Malaysia (lane M). Superior mutants sequence as follows: E-20-19, M-40-12, M-40-15, M-40-18 and S-60-8.

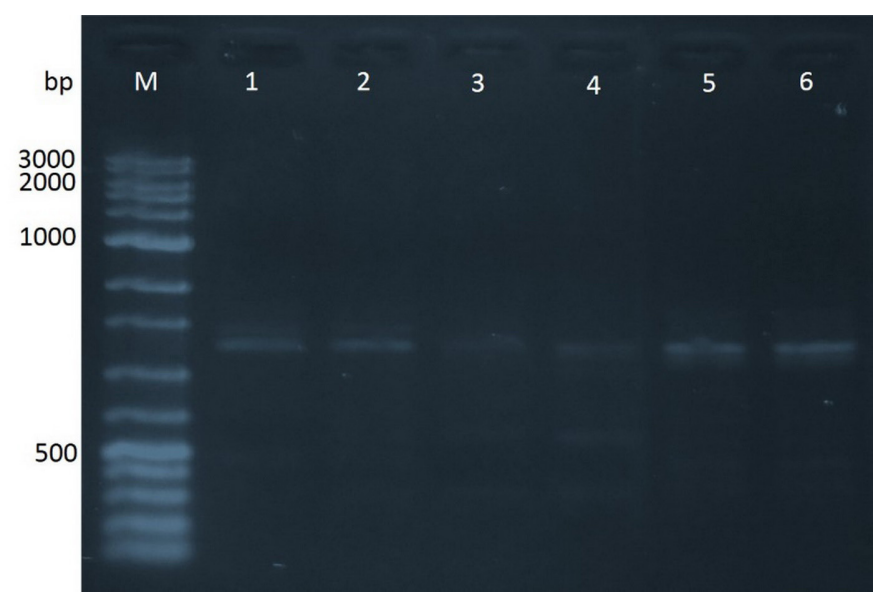

Fig. 3: DNA Photograph amplified profiles by RAPD for five best mutants (Lanes 2 to 6) and S. lincolnensis W.T (lane 1) using primer (P2) against VC100 bp plus DNA ladder Vivantis \# NL 1407-Malaysia (lane M). Superior mutants sequence as follows: E-20-19, M-40-12, M-40-15, M-40-18 and S-60-8.

With regarding to using primer No. 3 (Figure 4), it was clearly noticed that no amplified bands were detected when the DNA of mutants (Lanes 2 and 3) and the wild strain (Lane 1) were used as a templates. Moreover, the mutant (lane 4) exhibited two very faint amplified bands with sizes of $\sim 400$ and $700 \mathrm{bp}$. Finally, amplified distinct band $\sim 500 \mathrm{bp}$ was detected when the DNA of mutants (Lanes 5 and 6) were used as a templates. 


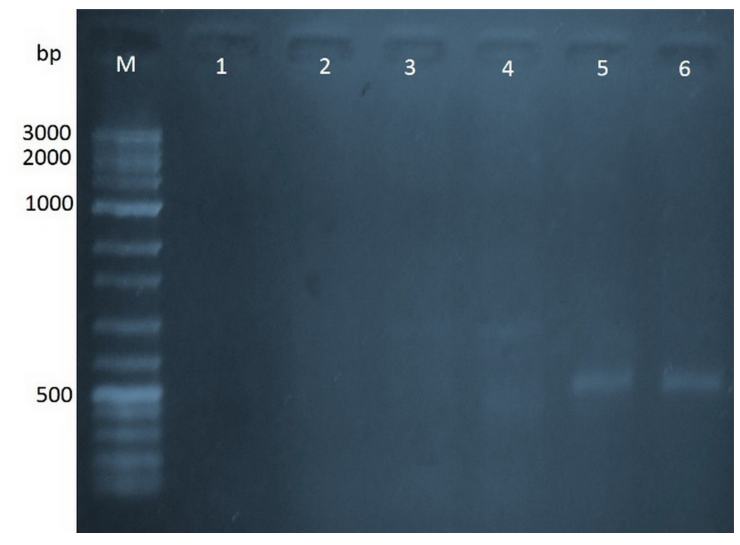

Fig. 4: DNA Photograph amplified profiles by RAPD for five best mutants (Lanes 2 to 6) and S. lincolnensis W.T (lane 1) using primer (P3) against VC100 bp plus DNA ladder Vivantis \# NL 1407-Malaysia (lane M). Superior mutants sequence as follows: E-20-19, M-40-12, M-40-15, M-40-18 and S-60-8.

The above RAPD variabilities proved that the genetic variations after mutagenesis in $S$. lincolnensis mutants are occurred. Also, many of these variation obtained by RAPD, could be useful for assessment the genetic markers for screening of the new mutants after mutagenesis. The study results were in agreement with those obtained by Subedi et al., 2015. Our study is the first to examine the mutagenesis response of $S$. lincolnensis NRRL 2936 and study the probability of change in RAPD profiles in relation to the improvement of Lincomycin production.

\section{CONCLUSION}

Improvement in lincomycin production by S. lincolnensis mutants after mutagenesis was obtained according this work. Also, differences in some superior mutants RAPD patterns comparison with the wild type strain were obtained by the PCR protocol and these differences at the same time proved as evidence of genetic variability of $S$. lincolnensis mutant strains.

\section{REFERENCES}

Anandan R., Dharumadurai D. and Manogaran G. P. An Introduction to Actinobacteria. In: Dhanasekaran D, Jiang Y (eds) Actinobacteria: Basics and Biotechnological Applications. Intech, Rijeka. 2016; pp. 3-37.

Choi D. and Cho K. Effect of carbon source consumption rate on lincomycin production from Streptomyces lincolnensis. J. Microbiol. Biotechnol., 2004; 14: 532-539.

El-Bondkly A.M. and Khattab A.A. Clavulanic acid and cephamycin improvement in Streptomyces clavuligerus by inducing combined resistant mutations and protoplast fusion. Egypt J. Genet. Cytol., 2004; 33: 217-230.

Hassan AA, El-Barawy AM, El Mokhtar MN. Evaluation of biological compounds of Streptomyces species for control of some fungal diseases. J. Am. Sci., 2011; 7(4):752-760.

Hwang B.K., Lim S.W., Kim B.S., Lee J.Y. and Moon S.S. Isolation and in vitro antifungal activity of phenylacetic acid and sodium phenylacetate Streptomyces humidus. Appl. Environ. Microbiol., 2001; 67: 3739-3745.

Ikeh E.I. Methicilin-resistant Staphylococcus aureus (MRSA) at Jos University Teaching Hospital. African J. Clinic. Exp. Microbiol., 2003; 4: 52-55.

Jensen PR, Dwight RY, Fenical W. Distribution of actinomycetes in near-shore tropical marine sediments. Appl. Environ.
Microbiol., 1991; 57(4):1102-1108.

Jensen PR, Williams PG, Oh DC, Zeigler L, Fenical W. Species-specific secondary metabolite production in marine actinomycetes of the genus Salinispora. Appl. Environ. Microbiol., 2007; 73(4):1146-1152.

Jin Z.H., Lin J.P., Xu Z.N. and Cen P.L. Improvement of industry-applied rifamycin B-producing strain, Amycolatopsis mediterranei, by rational screening. J. Gen.Appl. Microbiol., 2002a; 48: 329-334.

Jin Z.H., Wang M.R. and Cen P.L. Production of teicoplanin by valine analogue-resistant mutant strains of Actinoplanes teichomyceticus. Appl. Microbiol. Biotechnol., 2002b; 58: 63-66.

Khattab A. A. Genetic construction of superior strains of Streptomyces kanamyceticus for kanamycin production. Egypt J. Biotechnol., 2011; 39: 95-109.

Khattab A. A. and El-Bondkly A.M. Construction of superior Streptomyces noursei fusants for nystatin and antibacterial antibiotic production. Arab J. Biotechnol., 2006; 9: 95-106.

Koberska M., Kopecky J., Olsovska J., Jelinkova M., Ulanova D., Man P., Flieger M., Janata J. Sequence Analysis and Heterologous Expression of the Lincomycin Biosynthetic Cluster of the Type Strain Streptomyces lincolnensis ATCC 25466. Folia Microbiol., 2008; 53: $395-401$.

Krzek J., Anna K., Starek M., kierszniewska A., and Rzeszutko W. Identification and Determination of Oxytetracycline, Tiamulin, Lincomycin, and Spectinomycin in Veterinary Preparations by Thin-Layer Chromatography / Densitometry. J.AOAC Int., 2000; 83: 15021506

Kuo M.S., Yurek D.A., Coats J.H., Chung S.T. and Li G.P. Isolation and identification of 3-propylidene-delta 1-pyrroline-5carboxylic acid, a biosynthetic precursor of lincomycin. J Antibiot., 1992; 45:1773-1777.

Lee Y., Lee Mi-Ja, Choi Yoon-E., Chun Gie-Taek, and Jeong Yong-Seob. Optimization of Cultivation Medium and Fermentation Parameters for Lincomycin Production by Streptomyces lincolnensis. Biotechnol. Biopr. Eng., 2014; 19: 1014-1021.

Majerčíková K., Labuda R., Jaunecker G., Javoreková S. The glucose effect on lincomycin production by streptomyces lincolnensis var. lincolnensis dms 40355 on synthetic media. J. Microbiol. Biotech. Food Sci., 2015; 4 (4): 306-309.

Ramesh S, Mathivanan N. Screening of marine actinomycetes isolated from the Bay of Bengal, India for antimicrobial activity and industrial enzymes. World J. Microbiol. Biotechnol., 2009; 25(12):2103-2111.

Sambrook, J., Fritsch E.F. and Maniatis T. Molecular cloning: A laboratory Manual, Second Edition. 1989. New York: Cold Spring Harbor.

Semenova L.E., Sherstobitova T.S. and Gorokhova I.B. The development of a technology for lincomycin biosynthesis with batchtype feeding the substrates during the process. Antibiot. Khimioter, 1994; 39: 3-8.

Spizek J. and Rezanka T. Lincomycin, clindamycin and their applications. Appl. Microbiol. Biotechnol., 2004a; 64: 455-464.

Spizek J. and Rezanka T. Lincomycin, cultivation of producing strains and biosynthesis. Appl. Microbiol. Biotechnol., 2004b; 63:510-519.

Subedi P., Simon S., Rubin T. M., Bharat P. and Kiran B. T. Sodium azide induced mutaion of Actinomycetes II: Biochemical and Genetic Characterization. World J. Pharm. Sci., 2015; 3: 355-360.

Thoma R.W. Use of mutagens in the improvement of production strains of microorganisms. Folia Microbiol., 1971; 16: 197-204.

Williams J.K.G., Kubelik A.R., Livak K.J., Rafalski J.A. and Tingev S.V. DNA polymorphisms amplified by arbitrary primers are useful as genetic markers. Nucleic Acids Res., 1990; 18: 6531-6535.

Xiang-Jing W., Xiao-Chong W. and Wen-Sheng $\mathrm{X}$. Improvement of milbemycin-producing Streptomyces 
bingchenggensis by rational screening of ultraviolet- and chemically induced mutants. World J. Microbiol. Biotechnol., 2009; 25: 10511056.

Xuewei P., Zheng Y., Qiao X., Mao Q., Ma Q. and Ruifang Y. Improvement of Lincomycin Production by Mutant Selection and Metabolic Regulation. Prep Biochem Biotechnol. 2016; DOI: 10.1080/10826068.2016.1207083.

Young M.D. and Kempe L.L. Effects of Phosphate, Glucose, and Ammonium on Cell Growth and Lincomycin Production by Streptomyces lincolnensis in Chemically Defined Media. Biotechnol. Bioeng., 1985; 27: $327-$ 333.

Young M.D., Kempe L.L. and Bader F. G. Effects of phosphate, glucose and ammonium on cell growth and lincomycin production by streptomyces lincolnensis in chemically defined media. Biotechnol. Bioeng.,
1985; 27: 327-33.

ZheJ.andRuishenJ.Purificationandpropertiesofglutamatesynthase from Streptomyces lincolnensis. SCI. CHINA (Series C), 1998; 41: 37-46.

Zhihua J., Yinlin L., Jianping L. and Peilin C. Improvement of pristinamycin-producing Streptomyces pristinaespiralis by rational screening. World J. Microbiol. Biotechnol., 2006; 22: 129-134.

How to cite this article:

El-Sherbini A and Khattab AA. Induction of novel mutants of Streptomyces lincolnensis with high Lincomycin production. J App Pharm Sci, 2018; 8(02): 128-135. 